\title{
ENTRE O EXCESSO E A CONCISÃO: OS ESTILOS DE SARAMAGO E CARDOSO PIRES
}

\author{
Caio Yurgel ${ }^{1}$
}

RESUMO: O presente artigo busca contrapor dois estilos situados em extremos opostos do espectro literário: o excesso e a concisão. E, para tanto, parte de obras de dois autores portugueses, dois Josés: Saramago e Cardoso Pires. O primeiro deles admite o excesso de seus métodos, ao passo que o segundo alega optar pela concisão. É esta segunda afirmação que se planeja refutar aqui, demonstrando a força arquitetônica do excesso que subjaz à prosa de Cardoso Pires. Ademais, não é objetivo do artigo o de provar a supremacia de um estilo literário sobre o outro (uma tarefa em tudo inútil - não estamos aqui inseridos em um sistema dialético que buscará extrair uma síntese de dois polos opostos), mas sim o de apontar para alguns valores inerentes a uma literatura do excesso - um excesso, como veremos, que diz mais respeito à construção de um mundo ao leitor, de uma cidade que possa ser habitada por ele, e menos a malabarismos linguísticos.

PALAVRAS-CHAVE: Cardoso Pires; Concisão; Excesso; Literatura portuguesa; Saramago.

\section{BETWEEN EXCESS AND CONCISION: THE STYLE OF SARAMAGO AND CARDOSO PIRES}

\begin{abstract}
The article seeks to oppose two kinds of style situated at opposite sides of the literary spectrum: excess and concision. In order to do that, it establishes as a starting point the work of Portuguese writers José Saramago and José Cardoso Pires. While the first writer admit the excess behind his methods, the second pledges concision - an affirmation that is here rejected, in view of the architectonical strength that lies behind Cardoso Pires prose. Furthermore, this article does not intend to pitch one style against the other (a futile endeavor, given we're not locked inside a dialectical system that should seek synthesis out of opposing positions), but to point out some values inherent to a excess-prone literature - an excess that is more concerned in building a world for the reader, a city that he or she may inhabit, than empty linguistic games.
\end{abstract}

KEYWORDS: Cardoso Pires; Concision; Excess; Portuguese literature; Saramago.

\footnotetext{
${ }^{1}$ Graduado em Filosofia, bolsista CNPQ do Mestrado em Teoria da Literatura / Escrita Criativa pela Pontifícia
} Universidade Católica do Rio Grande do Sul (PUCRS). Contato: caio.yurgel@gmail.com 
A cadeira começou a cair, a ir abaixo, a tombar, mas não, no rigor do termo, a desabar. Em sentido estrito, desabar significa caírem as abas a. Ora, de uma cadeira não se dirá que tem abas, e se as tiver, por exemplo, uns apoios laterais para os braços, dir-se-á que estão caindo os braços da cadeira e não que desabam. Mas verdade é que desabam chuvadas, digo também, ou lembro já, para que não aconteça cair em minhas próprias armadilhas: assim, se desabam bátegas, que é apenas modo diferente de dizer o mesmo, não poderiam afinal desabar cadeiras, mesmo abas não tendo? Ao menos por liberdade poética? Ao menos por singelo artifício de um dizer que se proclama estilo? (SARAMAGO, 1984, p.13)

Não são propriamente as longas frases de Saramago que constituem o estilo do excesso, mas sim a manobra que as precede, o espaço que o escritor cria para si - o espaço que o escritor cria para o estilo. A manobra que precede o texto (e que permite que Saramago seja Saramago) é uma em busca de voz própria, é a prática de uma nuance, e não o efeito fácil de uma fórmula pronta. Significa abordar a escrita pelo que ela pode oferecer de diferença; significa pecar por tentativa, e não por anemia. Comparado à concisão, o excesso tende mais ao autoral, dota-se de maior personalidade narrativa. Em cinema, tende-se a opor o cinema de autor, como é o caso da Nouvelle vague, ao cinema de massa (Hollywood), e tal distinção, guardadas as devidas proporções, parece aplicar-se aqui. A aposta por Hollywood é a na segurança dos finais felizes e na repetição de recursos narrativos; a aposta pela Nouvelle vague é a na sutileza dos finais abertos e no risco de ser exposto a longos silêncios reflexivos entrecortados por uma voz em off e imagens de um casal em vias de fumar um cigarro. A literatura do excesso evita prender-se a estruturas pré-definidas para, assim, permitir-se digressões e nuances. Nas palavras de Roland Barthes: "Vocês sabem que há uma crise de estilo: prática e teórica (não há nenhuma teoria do estilo, e alguns se preocupam com isso). Ora, poderíamos definir o estilo como a prática escrita da nuance (por isso o estilo é malvisto hoje)" (BARTHES, 2005, p.94).

Além da extensão das frases (embora se recomende parcimônia - a prosa labiríntica de Proust não mais cabe no século XXI), das digressões inesperadas, trata-se de uma prática sobretudo interessada nos detalhes. O ponto-e-vírgula, por exemplo, rechaçado pela literatura da concisão - esta que trabalha a partir de formas binárias e que se satisfaz com vírgula e ponto final -, encontra espaço na literatura do excesso. Ela insere no texto uma quebra, um muito pequeno contrassenso (até mesmo um anacronismo gráfico), e impede a narrativa de sucumbir à ditadura do desfecho, permite ao escritor abandonar a linha reta do enredo e conduzir o 
leitor por caminhos menos pragmáticos e finalistas. A prática da nuance, o elogio do detalhe, serve como contraponto a um tipo de literatura despida de todo elemento supérfluo, de toda marca autoral, praticamente travestida em roteiro de cinema. A indagação permanece aqui em aberto: ganharia a literatura ao incorporar a lógica visual da televisão e do cinema? (Ou Marshall McLuhan tem razão e "o meio é a mensagem”?²)

O critico literário José Castello comenta, acerca dos Cadernos de Lanzarote de Saramago, que a obra "desperta nos leitores uma relação que não é habitual na literatura contemporânea, muito marcada por certo distanciamento cínico, ou certo temor dos sentimentos: a de grande intimidade" (CASTELLO, 1999, p.224). Qualquer manifestação de intimidade é personalista, ou seja, pressupõe uma personalidade à qual se reportar e com a qual estabelecer uma ligação intensa e recíproca. A intimidade refere-se, em certa medida, a uma generosidade, a uma sensação de acolhida - duas impressões comuns às obras de Saramago. Em literatura, a intimidade revela atenção ao leitor, revela a criação de um espaço (o livro) rico em diálogo, um que prevê o leitor sem anular o escritor (que permite ao escritor exibir seu estojo de ferramentas intelectuais, mas que não deixa o estojo cair sobre a cabeça do leitor desavisado este que buscava uma boa leitura e acabou perdido dentro de um jogo metaliterário).

E aqui José Saramago chega a uma fórmula: foram os leitores, e não os livros, que o transformaram em escritor. Em outras palavras: ele só se convenceu de que era escritor quando descobriu que tinha leitores e uma corrente de afeto começou a se manifestar entre eles. Livros sem leitores não existem, são apenas um amontoado de papel. "Não sou desses que escrevem sem pensar no leitor", afirma. Saramago diz não compreender o ponto de vista daqueles que escrevem pensando na posteridade, e não no presente, erro a seu ver muito perigoso, já que ninguém pode ter certeza de que a posteridade vai, de fato, se interessar por aquilo que hoje se faz. Se não tivesse a esperança de que seus contemporâneos se interessariam pelo que escreve, não conseguiria escrever; a idéia de posteridade, por si, não lhe traria nenhum tipo de consolo. (CASTELLO, 1999, p.217-218)

Saramago não apenas se alia ao que aqui denomino literatura de excesso pelo lado do estilo (a prática da nuance, em suma), mas também pelo lado ideológico (na ausência de melhor termo): o desinteresse pela posteridade; a desmistificação do conceito de literatura (e de

\footnotetext{
${ }^{2} \mathrm{O}$ teórico canadense Marshall McLuhan defende em Understanding media: The extensions of man (originalmente publicado em 1964, e retomado em The medium is the message, de 1967) a tese de que o meio torna-se um fator determinante nos processos de comunicação. Ou seja: os conteúdos são modificados em função dos meios (das formas) que os veiculam. Assim, uma mesma informação transmitida por um telejornal e por um jornal impresso não será percebida da mesma forma pelo telespectador/leitor.
} 
qualquer arte) como ainda transcendente; a visão da literatura como uma manifestação dentre muitas, uma que divide a restrita atenção de um restrito público com tantas outras, e portanto, uma manifestação que deve ser atraente, cativante, capaz de aliar entretenimento à reflexão crítica. Ou, nas contundentes palavras de Jean Genet, em visita ao ateliê do artista plástico Alberto Giacometti: "Não compreendo bem o que em arte se chama um inovador. Uma obra deveria ser compreendida pelas gerações futuras? Mas por quê? E o que isso significaria? Que elas poderiam utilizá-la? Para quê? Não entendo” (GENET, 2003, p.14).

"Não há mais histórias a contar," sacramenta Saramago em entrevista ao mesmo José Castello. "Não tem muita importância a história que se conta. O que tem importância é a pessoa que está dentro do livro; no caso de um romance, o autor” (CASTELLO, 1999, p.212). Uma declaração derridariana - "Já dissemos, excetuando-se muito pouco, tudo o que queríamos dizer. Nosso léxico, em todo caso, não está longe de se esgotar. Excetuando esse suplemento, nossas questões nomeiam apenas a textura do texto, a leitura e a escritura, a maestria e o jogo" (DERRIDA, 1991, p.9) -, que põe em questão o já mencionado caráter autoral da literatura do excesso, tanto no espaço criado para a prática do estilo, quanto na afirmação da presença do autor. Uma afirmação que não se dá no mesmo plano daquela empreendida pelo escritor dito pós-moderno (este que se afirma para subverter o texto, convertê-lo em jogo de espelhos), mas em um outro, mais sutil: o plano do escritor enquanto produtor (ou, para retomar o título de um artigo escrito pelo próprio Saramago, apesar de os propósitos serem levemente distintos: $O$ autor como narrador), desmistificado, ciente da concorrência que outras formas de expressão impõem à literatura, ciente da transitoriedade e da temporalidade de sua própria obra, e disposto ainda assim a produzir o melhor livro do qual é capaz: ambicioso e não anêmico; amplo e não abreviado.

Mas este mesmo romance, que assim pareço estar condenando, contém acaso em si, e já nos seus diferentes e actuais avatares, a aberta possibilidade de se transformar no lugar literário [...] capaz de receber como um grande, convulso e sonoro mar, os afluentes torrenciais da poesia, do drama, do ensaio, e também da ciência e da filosofia, tornando-se expressão de um conhecimento, de uma sabedoria, de uma cosmovisão, como o foram, para o seu tempo, os poemas da antiguidade clássica.

Porventura estarei caindo em erro, se tivermos em conta a crescente e parece que irreversível especialização, já quase microscópica, do homem. Porém, não é impossível que essa própria especialização, por força de conhecidos mecanismos ou impulsos de compensação, e talvez como instintiva condição de sobrevivência e de equilíbrio psicológico, nos leve a procurar uma nova 
vertigem do geral em oposição às aparentes seguranças do particular. Literariamente, porque só de literatura estamos aqui falando, talvez o romance possa restituir-nos essa vertigem suprema, o alto extático canto duma humanidade que ainda não foi capaz, até hoje, de conciliar-se com a sua própria face. (SARAMAGO, 1994, p.122)

O excesso entendido como polissemia, expansão, pluralidade - um sentido de plural que deturpo do de Barthes: "Interpretar um texto não é dar-lhe um sentido; é, ao contrário, apreciar de qual plural ele é feito” (BARTHES, 1970, p.11). O elogio do excesso tenciona corroborar Mikhail Bakhtin, quando este afirma que "O romance deve ser para o mundo contemporâneo aquilo que a epopeia foi para o mundo antigo" (BAKHTIN, 1998, p.403) - o que, em última análise, significa afirmar o valor da literatura como meio expressivo, sua atualidade mas não - eis o lado melancólico do excesso - sua eternidade. A literatura do excesso não teme em demonstrar que necessita do leitor, que não deseja alijá-lo da experiência literária. Toda literatura, afinal de contas, é um exercício de leitura: o escritor, antes de sê-lo, foi - e continua sendo, sempre - leitor, como o próprio Saramago foi leitor de Garrett (CASTELLO, 1999, p. 219). E, enquanto leitor, o escritor sabe quais textos o acolheram, e quais o rechaçaram; identifica as instâncias de intimidade e de intelectualidade; sintetiza as influências que, de alguma maneira, nortearão suas escolhas literárias. Um ciclo sobremaneira importante à literatura do excesso, pois esta reconhece o prazer da leitura (o prazer do leitor) e busca sintetizá-lo em novas formas (a tarefa do escritor) - sem, entretanto (espera-se), sucumbir à acomodação do consumo de massa, ao padrão de leitura do leitor-em-férias. Pela graça da polêmica, a literatura do excesso afirma que literatura é menos científica e mais compreensiva, isto é, menos neurótica com classificação de gêneros e mais afeita a reconhecer um bom texto onde um bom texto há.

O lugar da literatura, para revisitar o termo empregado por Saramago, é um de afluência, de síntese, e disso não há melhor testemunho (e em grande parte porque a época permitia) que as Viagens na minha terra, de Almeida Garrett. Cinquenta páginas texto adentro e enfim o autor julga prudente advertir o leitor: "Ainda assim, belas e amáveis leitoras, entendamo-nos: o que eu vou contar não é um romance, não tem aventuras enredadas, peripécias, situações e incidentes raros; é uma história simples e singela, sinceramente contada e sem pretensão" (GARRETT, 1992, p.50). Uma advertência que ecoa um dos mestres de Garrett, repetidas vezes citados no decurso das Viagens, o genial (e algo intraduzível) escritor 
inglês Laurence Sterne: "Isto para rechaçar um gosto perverso que tomou conta de milhares [...] - de ler sempre em linha reta, mais em busca de aventuras do que do profundo conhecimento e erudição que um livro deste porte, se lido como deveria ser, infalivelmente lhes transmitiria" (STERNE, 2010, p.48).

Há, em Garrett, elementos-chave que contribuem à reflexão sobre a construção de cidades imaginárias na obra de Cardoso Pires. O primeiro desses elementos já está contido nas citações acima, e a ele pode-se complementar com uma observação que Garrett faz acerca de seu próprio livro, logo no princípio da narrativa: "Numa regata de vapores o nosso barco não ganhava decerto o prêmio" (GARRETTT, 1992, p.20). Isto é, Garrett recusa a ditadura do desfecho, recusa reduzir sua narrativa ao estritamente essencial. A famosa (e talvez apócrifa) máxima de Anton Tchékhov segundo a qual um revólver não pode ser introduzido no primeiro ato se não vier a ser utilizado no terceiro revela-se aqui inútil: Garrett introduz incontáveis revólveres, e deixa-os todos espalhados e abandonados pelos capítulos. O romance (não se fala aqui de contos) não se justifica no desfecho, mas no trajeto. Um romance que recusa toda porta que não for fundamental ao enredo acaba por tornar-se frio e abstrato, carente de carne e osso. A literatura do excesso está pouco interessada em vencer a regata, pois sabe que seu esporte não são os cem metros rasos, sabe que sua forma não é aquela de um programa de televisão. Sua vitória se dá na sensação de lástima suscitada ao nos aproximarmos do final de um livro, a sensação de que poderíamos prosseguir naquela história independentemente do desfecho. Desfechos são importantes para anedotas. A literatura deve almejar um pouco além.

O segundo dos elementos-chaves desdobra-se do primeiro, decorre dos desvios tomados ao longo do caminho, diz respeito à quebra de um ritmo. A literatura da concisão vive pelo ritmo, pela manutenção deste mesmo ritmo - o que acaba por decorrer naturalmente de suas escolhas estilísticas: por simplificar o espectro gramatical, a literatura da concisão diminui a gama de recursos de rompimento, de inserção de pequenos movimentos de contrassenso que peguem o leitor desprevenido - ela torna-se continuidade e ordenamento lógico. Em Garrett, por outro lado, a quebra beira o excessivo. Em duas situações (poderiam ser muitas mais), ao introduzir novas personagens ao texto, o escritor português interrompe a narrativa para anunciar que tomará um novo rumo: "Saibamos alguma coisa desta vida" (GARRETT, 1992, p.68), ou ainda: “O oficial... - Mas certo que as amáveis leitoras querem 
saber com quem tratam, e exigem, pelo menos, uma esquiça rápida e a largos traços do novo ator que lhes vou apresentar em cena” (GARRETT, 1992, p.83). Isto é, o texto não obedece a uma sequência lógica que lhe poderia ser presumida - ele é nuançado, plural, assistemático e melancólico. Melancólico como o dono da festa, sozinho no salão depois que todos já partiram, depois que o excesso assentou-se (balões murchos e serpentina no chão). Melancólico porque desconfiado do mundo, de um mundo que faz progressivamente menos sentido, porém exige da literatura todo - todo sentido e mais um pouco. E essa melancolia, embora aliada ao esforço de comunicação (pois que insistir na figura do leitor significa bem isso, uma tentativa de comunicar-se com alguém), permanece sempre muito avisada da fragilidade de seu empenho. Ela não pode recolocar ordem no mundo - a arte é em grande medida impotente diante das forças maiores do mundo (a religião, a política, a economia...), porém ela pode, sim, recriar algum diálogo, recriar um sentido de comunidade - e é aí que ela busca afirmar-se, em contraponto à fria e distanciada existência proposta pela concisão.

Detesto a filosofia, detesto a razão; e sinceramente creio que num mundo tão desconchavado como este, numa sociedade tão falsa, numa vida tão absurda com a que nos fazem as leis, os costumes, as instituições, as conveniências dela, afetar nas palavras a exatidão, a lógica, a retidão que não há nas coisas, é a maior e mais perniciosa de todas as incoerências. (GARRETT, 1992, p.142)

A afirmação de Garrett soa como uma ode, possui a grandiloquência e o orgulho típicos de uma ode. E ela o é, de alguma maneira, uma ode: um elogio à força narrativa, esta que não pode ser contida por estruturas e roteiros, esta que não recusa a nuance e os detalhes. “Que não me reprovem de ser prolixo nos detalhes," escreve Xavier de Maistre: “é a maneira dos viajantes" (DE MAISTRE, 2004, p.30). E é do francês De Maistre de quem Garrett toma a inspiração para sua ode, uma ode ao ziguezague e à abertura da alma às coisas que se apresentam pelo caminho:

Não gosto das pessoas que são a tal ponto mestres de seus passos e de suas ideias que dizem: "Hoje, farei três visitas, escreverei quatro cartas, terminarei essa obra que comecei”. - Minha alma está tão aberta a toda sorte de ideias, de gostos e de sentimentos; ela acolhe avidamente tudo que se apresenta!... E porque haveria de recusar as alegrias que estão dispersas pelo difícil caminho da vida? Elas são tão raras, tão esporádicas, que seria preciso ser louco para não parar, até mesmo desviar do caminho, para colher todas aquelas que estão ao nosso alcance. (DE MAISTRE, 2004, p.10) 
De Maistre que surge logo à primeira página das Viagens na minha terra, e outra vez uma dezena de páginas depois, ocasião na qual Garrett diz ficar “como o bom Xavier de Maistre quando, a meia jornada de seu quarto, lhe perdeu a cadeira o equilíbrio, e ele caiu - ou ia caindo, já me não lembro bem - estatelado no chão” (GARRETTT, 1992, p.33).

E desde o início deste artigo a cadeira já caía, e ainda não cessou de cair completamente. Ainda cai, e cai sempre, e cairá por quanto tempo desejarmos que caia. E nessa suspensão deixamos Saramago com Garrett, Garrett com De Maistre, todos póstumos apesar de tudo, e seguimos nosso viagem rumo à conclusão (apesar de tudo).

"Nada mais importante para chamar a atenção sobre uma verdade do que exagerá-la," afirma Antonio Candido (CANDIDO, 2008, p.13), e sob a égide de sua afirmação situo este derradeiro tópico de discussão: o exagero como método de criação literária, como método de construção de cidades ficcionais. E proponho o seguinte: que nem tudo está perdido - que mesmo um escritor conciso deve ser exagerado em seu processo de criação. Pois talvez a pior concisão não seja a verbal - a pior concisão é a concisão do imaginário.

Para tanto, tomo dois textos-chave do escritor português José Cardoso Pires como exemplo e contraponto (O Delfim e um texto crítico, exegético, sobre o próprio Delfim, intitulado Memória descritiva), e complemento-o com alguns dos teóricos já mencionados e ainda outros mais, já que um texto é feito de seu plural. Porém inicio não pela teoria, mas pela anedota, por uma breve constatação de Cardoso Pires em meio a uma entrevista concedida a José Castello: "Somos assim mesmo," disse o escritor português, "seres do exagero" (CASTELLO, 1999, p.250). Embora possa ser descartada por espíritos mais rigorosos como meramente anedótica, a declaração parece apontar para a força subjacente à (autodeclarada) concisão verbal de Cardoso Pires. Ademais, demonstra que a opção do escritor português por uma linguagem enxuta não é acompanhada de sua contrapartida mais perversa: a de uma imaginação igualmente restrita.

Uma rápida leitura de $O$ Delfim bastaria para comprovar o estilo conciso do escritor, e o próprio Cardoso Pires é o primeiro a admiti-lo sem meias-palavras:

Por mim, no que toca ao modo de narrar, prefiro correr o risco de jamais atingir o ponto impreciso da clareza e pecar por excesso, ultrapassando-a. Das duas faces desastrosas do gume a última parece-me a pior porque resvala para o tom impositivo que anula os valores da sugestão e que impede 
a leitura de se tornar em si mesma uma segunda criação. De resto, toda a ficção comunica em equações bem menos lineares do que o discurso das disciplinas científicas, por exemplo, ou o da informação convencional. O seu registro é diferente, a sua elongação mais ampla. Há nele permanências subjectivas, liberdades e incitações que o situam noutras zonas de leitura. (PIRES, 1999, p.118-119)

Trata-se aqui menos de rebater a posição de Cardoso Pires (o que, de todo modo, está feito na primeira metade do artigo), mas sim de explorar algumas consequências decorrentes da segunda metade da declaração do escritor, e de sua utilidade na discussão do exagero como método. Pois bastaria, novamente, uma rápida leitura de $O$ Delfim para que o leitor percebesse tratar-se de um mundo coerente e extenso aquele que se desvela por trás das páginas do livro, de modo que a linguagem empregada pelo escritor não se converte em uma afetação pósmoderna, mas em uma escolha consciente e justificada pelos valores que são os seus. Pois este é, em última análise, o risco maior da concisão: a superficialidade de seu imaginário, a opção por um estilo já pronto e de simples aplicação, um estilo que não acolhe o leitor e nem se converte "em uma segunda criação".

Nesse aspecto, Cardoso Pires demonstra suas leituras de Barthes - conforme ele próprio admite (PIRES, 1999, p.123) -, demonstra a centralidade do leitor na produção do texto literário: "Pois o que está em jogo no trabalho literário (da literatura como trabalho), é fazer do leitor, não mais um consumidor, mas um produtor do texto" (BARTHES, 1970, p.10). E a perversidade da literatura da concisão (imaginária e verbal) está em que muitas vezes esta não cria espaço para o leitor, não oferece subsídios além da superfície do texto. O benéfico exagero, em Cardoso Pires, encontra-se na criação desse espaço - O Delfim não é senão a criação de um mundo para seu leitor, de uma cidade provida de ruelas e vizinhos e igrejas e vidas, de onde advêm as muitas leituras que lhe podem ser feitas. A manobra do escritor português responde às propostas de Hayden White em seu The Content of Form: “O que busquei sugerir é que o valor atrelado à narratividade na representação de eventos reais deriva do desejo de que os eventos reais apresentem a coerência, integridade, plenitude e closure [encerramento] de uma imagem que só pode ser imaginária" (WHITE, 1987, p.24). Elementos estes que podem ser encontrados em abundância em Cardoso Pires, justamente porque o escritor prezou por uma abordagem que não se furtou de observar a riqueza do mundo real, derivando dele um universo ficcional, abundante e coerente, digno das páginas de um livro. 
Pois literatura não significa uma cópia literal da realidade, e sim uma reorganização ficcional (exagerada) desta mesma realidade. A própria colocação de White ecoa, outra vez, os escritos de Barthes:

Toda descrição literária é uma vista. [...] Descrever é pois colocar a moldura vazia que o escritor realista carrega sempre consigo [...] diante de uma coleção ou de um contínuo de objetos inacessíveis à palavra [...]; para poder falar desses objetos, é preciso que o escritor, através de um rito inicial, primeiro transforme o 'real' em objeto pintado (emoldurado); depois do que ele poderá desprender este objeto, extraí-lo de sua pintura [...]. Desta forma o realismo (bem mal nomeado, em todo caso com frequência mal interpretado) consiste não em copiar o real, mas em copiar uma copia (pintada) do real. (BARTHES, 1970, p.61)

A cópia da cópia, um mundo ficcional coeso e abundante que transpareça pelas páginas do livro e ao redor das quais o leitor possa construir-se, possa ter acesso a um manancial de experiências que lhe facultem múltiplas leituras. E um mundo ficcional que admita não ser mais que apenas isso: o ponto de vista de um autor, profundamente marcado por suas vicissitudes e escolhas, porém sem jamais impô-las totalitariamente ao leitor.

Paul Valéry resume-o muito bem em uma declaração que se encontra na base das afirmações de Barthes e, portanto, de White: “Observar é, em grande parte, imaginar o que esperamos ver" (VALÉRY, 2003, p.29). A cópia da cópia, mas uma cópia muito particular, uma que parte da realidade para expô-la, exagerar seus mecanismos e, assim, chamar a atenção do leitor para as perversidades do cotidiano. Pois a literatura do excesso atrela-se firmemente a uma concepção realista, de crítica social, e, nesse sentido, a observação de Valéry é fundamental para lembrar o escritor de que não basta descrever a realidade - é preciso exagerála, subvertê-la em algum nível, tentar muito para conseguir ao menos um pouco. Ou, nas palavras do filósofo francês Gaston Bachelard:

Como ela é injusta, a crítica que vê na linguagem apenas uma esclerose da experiência íntima! Pelo contrário, a linguagem está sempre um pouco adiante de nosso pensamento, é sempre um pouco mais borbulhante que nosso amor. [...] Por diversas vezes, no decorrer deste ensaio, sublinhamos o caráter dinâmico do exagero imaginário. Sem tal exagero, a vida não pode desenvolver-se. Em quaisquer circunstâncias, a vida toma muito para ter o bastante. É preciso que a imaginação tome muito para que o pensamento tenha o bastante. É preciso que a vontade imagine muito para realizar o bastante. (BACHELARD, 2007, p.329-330) 
Imaginar muito para realizar o suficiente - eis o calcanhar-de-aquiles da concisão: faltalhe estofo, ambição, fôlego. De tal forma preocupada em manter-se dentro de sua fórmula, de sua forma, que se esquece do essencial, do leitor, da experiência viva que toda narrativa digna deve constituir. Pois nem tudo é esquematização, nem tudo é teoria, nem tudo é incomunicabilidade pós-moderna: a melhor maneira de se escrever literatura é escrevendo-a, é permitindo-se abandonar as amarras de uma linearidade excessiva e de um racionalismo científico e aceitando os desvios que o caminho forçosamente efetuará.

E escrever ficção não é propriamente levantar um edifício racionalizado pedra a pedra. Por mais pessoal que seja a voz do novelista, por mais experiência que ele tenha no ofício de contar, cada romance é sempre a busca duma organização e duma forma que há-de nascer da estória que ele tem para transmitir. (PIRES, 1999, p.120)

O excesso, portanto. De forma e de conteúdo. A profundidade narrativa. A recusa de uma lógica padronizada. Um pendor bakhtiniano à recriação de uma espécie de épico contemporâneo. O contrassenso como tática. O exagero como método. E se ainda nada disso for suficiente para convencer o leitor do valor do excesso, proponho abraçar o contrassenso e trocar as atuais páginas por apenas duas linhas do escritor e teórico americano Abraham Verghese: "Gosto de histórias épicas porque nelas você acompanha gerações inteiras e, quando fecha o livro, ainda é terça-feira" (2011, s/p).

\section{BIBLIOGRAFIA}

BACHELARD, Gaston. L'air et les songes. Paris: Le Livre de Poche, 2007.

BAKHTIN, Mikhail. Questões de literatura e de estética: a teoria do romance. Trad. Aurora F. Bernardini. São Paulo: HUCITEC, 1998.

BARTHES, Roland. A preparação do romance, vol. I. Trad. Leyla Perrone-Moisés. São Paulo: Martins Fontes, 2005.

S/Z. Paris: Seuil, 1970.

CANDIDO, Antonio. Literatura e sociedade. Rio de Janeiro: Ouro sobre Azul, 2008.

CASTELLO, José. Inventário das sombras. Rio de Janeiro: Record, 1999.

DE MAISTRE, Xavier. Voyage autour de ma chambre. Paris: Ebooks Libres et Gratuits, 2004.

Disponível em: < http://www.ebooksgratuits.com/ > 
DERRIDA, Jacques. A farmácia de Platão. Trad. Rogério Costa. São Paulo: Iluminuras, 1991.

GARRETT, Almeida. Viagens na minha terra. São Paulo: Editora Núcleo, 1992.

GENET, Jean. O ateliê de Giacometti. Trad. Célia Euvaldo. São Paulo: Cosac Naify, 2003.

MCLUHAN, Marshall. Understanding media: The extensions of man. Cambridge: MIT Press, 1994.

PIRES, José Cardoso. O Delfim. Rio de Janeiro: Civilização Brasileira, 1983. . E agora, José? Lisboa: Dom Quixote, 1999.

SARAMAGO, José. Objecto quase. Lisboa: Caminho, 1984.

. Do canto ao romance, do romance ao canto. In: Bulletin of Hispanic Studies, Liverpool, v.71, n.1, p.119-123, 1994.

. O autor como narrador. In: Ler, Lisboa, n.38, p.38-41, primavera-verão 1997.

STERNE, Laurence. The life and opinions of Tristram Shandy, Gentleman. Oxford: Oxford University Press, 2010.

VALÉRY, Paul. Degas dança desenho. Trad. Célia Euvaldo. São Paulo: Cosac Naify, 2003.

WHITE, Hayden. The content of form. Baltimore: Johns Hopkins University Press, 1987.

VERGHESE, Abraham. In: Prosa \& Verso, 03/09/2011. Disponível em: < http://oglobo.globo.com/ blogs/prosa/posts/2011/09/03/as-afinidades-de-amitav-ghoshabraham-verghese-403214.asp >

\section{Artigo recebido em 21 de Agosto de 2012.}

Artigo aprovado em 27 de Outubro de 2012. 